\title{
The Minamata Convention
}

\section{A tool for global regulation of mercury pollution}

\author{
by Eisaku Toda, Claudia ten Have, and \\ Jozef M. Pacyna
}

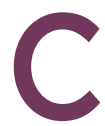

onsiderable scientific knowledge has been developed on sources and emissions of mercury, its pathways and cycling through the environment, human exposure and impacts on human health. Mercury has been recognized as a toxic, persistent, and mobile contaminant. This contaminant does not degrade in the environment, and it is mobile because of the volatility of the element and several of its compounds. Mercury has the ability to be transported within air masses over very long distances and deposited far away from emission sources.

\section{Current emissions and environmental fluxes of mercury}

Although mercury is a naturally occurring element, the United Nations Environment Programme (UNEP) Report (UNEP, 2019) indicates that the level of mercury in the atmospheric environment is 450 percent higher than the natural level, including the contribution of historical anthropogenic emission. Current emission inventories of anthropogenic sources indicate the total global anthropogenic emission accounts for 2225 tonnes per year (for the year 2015) and that major point source categories include artisanal and smallscale gold mining (ASGM), coal-fired power plants and coal-fired boilers, non-ferrous metals production, waste incineration and cement clinker production. Emission source contribution estimates for the year 2015 are presented in Fig. 1.

Current estimates of mercury emissions from natural sources and re-emissions, including mercury depletion events, were reviewed in Pacyna et al. (2016). The total emission amount of about 5200 metric tonnes per year was estimated, which represent nearly $70 \%$ of the global total mercury emissions. Oceans are the most important sources among natural and reemission sources, contributing $36 \%$ to the emissions of mercury, followed by biomass burning ( $9 \%$ ), deserts, metalliferous and non-vegetated zones (7\%), tundra and grassland (6\%), forests (5\%), and evasion after mercury depletion events (3\%).

Once emitted to the environment, mercury travels a long distance within the atmosphere, deposits on land and water, and is partly re-emitted to the atmosphere from land and ocean surfaces. Another part of deposited mercury is methylated in the ecosystem, bioaccumulates in organisms and is transported within the food chain. In this pathway mercury finds its way to human body through contaminated food. Global mercury budget showing the anthropogenic impact on the $\mathrm{Hg}$ cycle since the pre-anthropogenic period (prior to 1450 AD) is presented in Fig. 2 after updates of various estimates prepared for the Arctic Monitoring and Assessment Programme (AMAP) and UNEP (UNEP, 2019).

Mercury exists in the environment in different forms, the most toxic being methylmercury. This is also the form that bioaccumulates in aquatic food chains. Consumption of fish is one of the most important exposure pathways for humans. It has been documented that a portion of humans and wildlife throughout the world are exposed to methylmercury at levels of concern (summarized in AMAP 2018, UNEP 2019). Elevated $\mathrm{Hg}$ exposures in key groups of people of concern include foetuses, Arctic populations, who regularly consume fish and marine mammals, tropical riverine communities, coastal and/or small-island communities that are high seafood consumers, and individuals who either work or live among artisanal and small-scale gold mining sites, or who otherwise have high occupational exposures (UNEP 2019).

Methylmercury is a developmental neurotoxicant at dangerously high environmental levels in many regions of the world. It can cause neurological effects, including reductions in $I Q$ among children. Among adults, neurobehavioral effects can be observed at moderately elevated exposures. There is also an evidence indicating

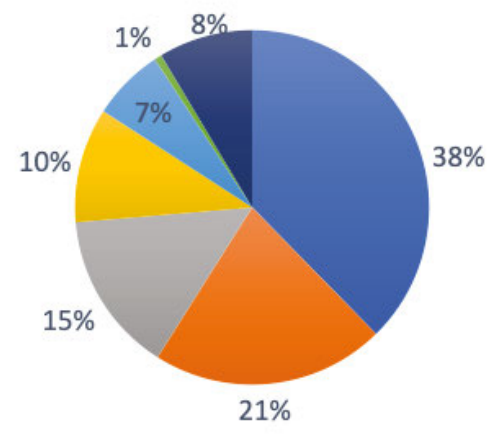

aSGM

- Stationary combustion of coal

Non-ferrous metals production $=$ Cement production

Waste from products Waste incineration

athers

Fig. 1: Estimated source contributions to anthropogenic mercury emission to air in 2015, in percentage (UNEP 2019) 


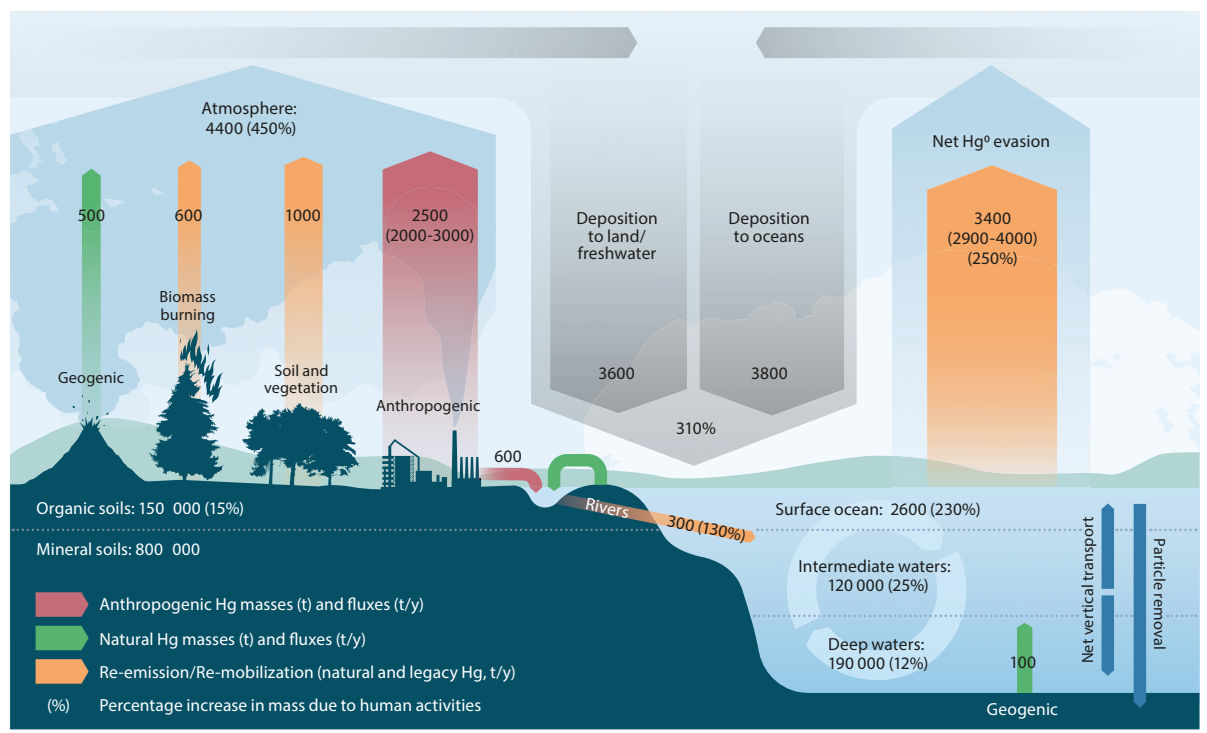

Fig. 2. Global mercury budget showing the anthropogenic impact on the $\mathrm{Hg}$ cycle since the pre-anthropogenic period, prior to 1450 AD, (UNEP 2019). Ranges are given in brackets after the best estimate values; percentages in brackets represent the estimated increase in mass or flux due to human activities since the pre-anthropogenic period.

elevated risk for cardiovascular diseases, especially myocardial infarction. In the case of severe exposure, there is a risk for reproductive outcomes, immune system effects and premature death.

\section{Future projections of mercury emissions}

Future projections for mercury emissions from anthropogenic sources are dependent on economic development in individual countries, particularly on energy production. There were already a few attempts to develop such projections, one of them by Pacyna et al. (2016). Reduction of mercury in the future can be achieved as a co-benefit when reducing emissions of sulfur and nitrogen oxides, greenhouse gases, as well as through implementation of mercury-specific controls. The choice of future non fossil energy sources will have large effects on mercury emissions: biomass combustion will continue to mobilize mercury present in the fuels (even if some of this mercury is natural), whereas non-combustion solutions such as solar or wind-based power generation will, of course, not cause additional emissions of mercury.

A comparison of the 2035 anthropogenic emissions estimated for various scenarios indicates that the 2010 emissions will remain the same in 2035 if mercury continues to be emitted under current control measures and practices (CP-current policy scenario). A full implementation of current and some new policy commitments and plans (NP-new policy scenario) will imply a benefit of reducing mercury emissions by up to $48 \%$ in 2035 compared to the emissions in 2010. An implementation of maximum feasible reduction of mercury emissions projection (MFR scenario) will result in $84 \%$ reduction of emissions in 2035 compared to 2010. It should be added, that both CP and NP scenarios do not include the Minamata Convention measures. Therefore, the scenario analysis should be repeated now when the Convention is in force.

Projections of future changes in mercury deposition on a global scale modelled for the CP, NP and MFR emissions scenarios of 2035 are also available (Pacyna et al., 2016). The CP scenario predicts a considerable decrease (20-30\%) of mercury deposition in Europe and North America and strong (up to $50 \%$ ) increase in South and East Asia. According to the NP scenario a moderate decrease in mercury deposition (20-30\%) is predicted over the whole of the globe except for South Asia (India), where an increase in deposition (10-15\%) is expected due to the growth of regional anthropogenic emissions. Model predictions based on the MFR scenario demonstrate consistent mercury deposition reduction on a global scale with a somewhat larger decrease in the Northern Hemisphere (35-50\%) and a smaller decrease (30-35\%) in the Southern Hemisphere. Thus, the most significant changes in mercury deposition (both increase and decrease) during the next 15 years for all considered scenarios are expected in the Northern Hemisphere and, in particular, in the largest industrial regions, where the majority of regulated emission sources are located.

\section{Development of Minamata Convention supported by science}

In the 1990s, the international community started to address mercury pollution as transboundary and global issue. The Aarhus Protocol on Heavy Metals under the Convention on Long-range Transboundary Air Pollution of the United Nations Economic Council 
Article 12: Contaminated sites

Guidance on management (COP-3)

Basel Convention guidelines
Article 3: Supply

Trade
Guidance on identifying mercury stocks (COP-1)

Guidance and format for import consent (COP-1)

Article 4: Products

Article 5: Processes

Article 7: ASGM NAP guidance (COP-1)
Life cycle of mercury
Article 8: Emissions BAT/BEP and inventory guidance (COP-1)

Article 9: Releases Inventory guidance (expected COP-4) for Europe was adopted in 1998. UNEP published its first Global Mercury Assessment in 2002, which presented information on chemistry, toxicity and risk of mercury, its production and use, environmental pathways, and preventive and control measures. The key findings of this first Assessment included the fact that mercury is affecting the environment far from any significant source of releases, that elevated methylmercury levels are observed in numerous freshwater and marine fish species, that mercury may be more problematic to less developed regions, and that actions implemented in Europe, North America and elsewhere have successfully reduced uses and releases of mercury. The Assessment estimated the global anthropogenic emission of mercury to the atmosphere at about 2,000 metric tonnes per year, $77 \%$ of which was attributed to stationary combustion of fuels.

Based on these key findings, the Governing Council of UNEP agreed at its 22nd meeting in 2003 that there is sufficient evidence of significant global adverse impacts from mercury to warrant further international action to reduce the risks to human health and the environment. The 23rd Governing Council in 2005 established a Global Mercury Partnership as a non-legally-binding mechanism to reduce the environmental and health risk of mercury. The 25th Governing Council in 2009 decided to elaborate a legally binding instrument on mercury, and established an intergovernmental negotiating committee (INC) with the mandate to prepare a global legally binding instrument by 2013. The INC, through five meetings, finalized the draft for the Minamata Convention on Mercury in January 2013. The Convention was formally adopted at the Conference of Plenipotentiaries held in Kumamoto, Japan on 10-11 October 2013, preceded by a ceremonial opening held in Minamata City.

The negotiation was supported by scientific and technical knowledge. UNEP presented the second Global Mercury Assessment (UNEP 2008) to the Governing Council, which formed the basis of the Council's decision to start the intergovernmental negotiation. The third Assessment (UNEP 2013) found that the emission from ASGM was the largest source of anthropogenic emission of mercury. UNEP also published two reports on global mercury supply, demand and trade (UNEP 2006 and 2017), and submitted a number of technical reports on mercury supply, trade, use, emissions and releases to the INC and other negotiation meetings.

The Minamata Convention consists of a preamble, 35 articles and 5 annexes. Its preamble recognizes the substantial lessons of Minamata Disease, widespread methylmercury poisoning around Minamata Bay of southern Japan, and the need to ensure proper management of mercury and the prevention of such events in the future. Article 1 sets out the objective of the Convention to protect the human health and the environment from anthropogenic emissions and releases of mercury and mercury compounds. Articles 3 to 12 establish the obligation of parties to control the whole life cycle of mercury-from its supply to trade, use, emissions, releases, storage, disposal and 


\section{A tool for global regulation of mercury pollution}

the management of contaminated sites (see Fig. 3). Articles 13 to 15 provide for measures to support the parties in implementing the Convention. Articles 16 to 20 relate to information and awareness raising. Articles 21 to 35 concern administrative and procedural matters regarding the Convention.

After the adoption of the Convention, the INC met twice to prepare for the entry into force and the implementation of the Convention. A technical expert group on emission was established to develop guidance documents on best available techniques and best environmental practices on the control of mercury emission to air, and on the development of emission inventory. The Global Mercury Partnership worked on the development of a guidance document on ASGM national action plans. Such work, involving scientific

$\begin{array}{lll}\text { Date } & \text { Article } & \text { Description } \\ 2018 & \begin{array}{l}\text { Art. 5, para. 2, and } \\ \text { annex B }\end{array} & \begin{array}{l}\text { Acetaldehyde production in which mercury or mercury compounds are used as a catalyst } \\ \text { is to be phased out. }\end{array}\end{array}$

Manufacture, import or export of various mercury-added products is no longer allowed (including batteries, switches and relays, compact and linear fluorescent lamps, high

Art. 4, para. 1, and annex $\mathrm{A}$

Art. 5, para. 3, and annex B

\begin{tabular}{|c|c|c|}
\hline \multirow{3}{*}{$2020^{*}$} & Art. 5, para. 5 (c) & $\begin{array}{l}\text { Submit to the secretariat, no later than three years after the date of entry into force for } \\
\text { the party, information on the number and types of facilities that use mercury or mercury } \\
\text { compounds for processes listed in annex B, and the estimated annual amount of mercury } \\
\text { or mercury compounds used in those facilities. }\end{array}$ \\
\hline & Art. 7, para. 3 (b) & $\begin{array}{l}\text { For a party that determines that ASGM in its territory is more than insignificant, submit } \\
\text { a national action plan to the secretariat no later than three years after the date of entry } \\
\text { into force for the party or three years after the party notifies the secretariat of its deter- } \\
\text { mination, whichever is later. }\end{array}$ \\
\hline & Art. 9, para. 3 & $\begin{array}{l}\text { Identify relevant point source categories no later than three years after the date of entry } \\
\text { into force for the party. }\end{array}$ \\
\hline $2021^{*}$ & $\begin{array}{l}\text { Arts. } 8 \text {, para. 3, and } \\
\text { art. } 9 \text {, para. } 4\end{array}$ & $\begin{array}{l}\text { Submit an implementation plan, if one has been developed, within four years of the date } \\
\text { of entry into force for the party. }\end{array}$ \\
\hline $2022^{*}$ & Art. 8, para. 4 & $\begin{array}{l}\text { For new sources, require the use of best available techniques and best environmental } \\
\text { practices no later than five years after the date of entry into force for the party. }\end{array}$ \\
\hline \multirow{2}{*}{$2023^{*}$} & Art. 8, para. 7 & $\begin{array}{l}\text { Establish and maintain an inventory of emissions sources no later than five years after the } \\
\text { date of entry into force for the party. }\end{array}$ \\
\hline & Art. 9, para. 6 & $\begin{array}{l}\text { Establish and maintain an inventory of release sources no later than five years after the } \\
\text { date of entry into force for the party. }\end{array}$ \\
\hline 2025 & $\begin{array}{l}\text { Art. } 5 \text {, para. 2, and } \\
\text { annex B }\end{array}$ & Chlor-alkali production is to be phased out. \\
\hline 2027 & $\begin{array}{l}\text { Art. } 5 \text {, para. } 3 \text {, and } \\
\text { annex } B\end{array}$ & $\begin{array}{l}\text { For sodium or potassium methylate or ethylate, reduce the use of mercury, aiming at } \\
\text { phase-out of this use as fast as possible and within } 10 \text { years of entry into force of the } \\
\text { Convention. }\end{array}$ \\
\hline $2027^{*}$ & Art. 8, para. 5 & $\begin{array}{l}\text { Implement control measures for existing facilities no more than } 10 \text { years after the date of } \\
\text { entry into force for the party. }\end{array}$ \\
\hline
\end{tabular}

Table 1: Minamata Convention timelines

* Denotes first possible date, depending on when the Convention entered into force for that party. 
and technical experts, resulted in the adoption of these guidance documents at the first meeting of its Conference of the Parties (COP), held in Geneva in September 2017. COP-1 established an ad hoc expert group on effectiveness evaluation (Article 22), and also put in place processes to involve experts nominated by parties and stakeholders on interim storage of mercury (Article 10), mercury waste thresholds (Article 11) and the management of contaminated sites (Article 12). COP-2, held in November 2018, adopted a guidance document on interims storage, and established expert groups on mercury releases to land and water (Article 9) and mercury waste thresholds. COP-3 in November 2019 adopted a guidance document on the management of contaminated sites, and established an expert group on the review of Annexes $A$ and $B$ which list mercury-added products and processes that use mercury.

Work on technical issues continues in preparation for COP-4 to be held in Bali, Indonesia in November 2021. The ad hoc group of experts on the review of Annexes $A$ and $B$ works on the compilation of information on alternatives to mercury-added products and manufacturing processes using mercury. The group is reviewing the information submitted by Parties and non-parties, and working to organize and enrich the information. The document will be used by COP-4 for reviewing the Annexes pursuant to the provisions of Articles 4 and 5 which require that the review be done no later than 2022.

The group on mercury release works on the identification of relevant point sources and the development of guidance on release inventory, pursuant to Article 9. The group reviews information on release estimation methods submitted by Parties and stakeholders, and plans to collect further information, as well as to pilot-test these methods. Parties have an obligation to submit release inventory no later than five years after the entry into force.

The group of technical experts on mercury waste thresholds works to establish thresholds for defining waste contaminated with mercury, starting with an analysis of three approaches to thresholds-total mercury concentration, exposure potential (e.g. leaching test) and qualitative determination (listing approach). The group will further work on specific threshold values for this category of waste, as well as on thresholds for tailings from ASGM and non-ferrous metals mining.

Although the Minamata Convention currently does not have permanent scientific advisory bodies, it is supported by scientific and technical knowledge provided through these technical groups and processes involving experts nominated by parties and other stakeholders.

\section{Initial implementation efforts by countries}

The Global Environment Facility, which is designated as part of the financial mechanism of the Minamata Convention, supports developing country parties and parties with economies in transition in developing Minamata Convention Initial Assessments (MIA), which consists of the following:

- National Mercury Profile, including identification of significant sources of emissions and releases, as well as inventories of mercury and mercury compounds;

- Overview of structures, institutions, and legislation already available to implement the Convention;

- Challenges to implementation, including identification of legal and/or regulatory gaps to be addressed prior to ratification; and

- Capacity building, technical assistance as well as other needs required for the implementation of the Convention.

MIA is intended for supporting the ratification and early implementation of the Convention. Minamata Convention has 128 signatories, which signed the Convention within one year after its adoption in 2013. Signatories become Parties by ratifying, accepting or approving the Convention. Non-signatories can become Parties by acceding to it. As of 1 June 2020, the Convention has 120 Parties and 37 Signatories have yet to ratify it (Fig. 4). The MIA project has been or is being implemented in 72 Parties and 42 non-parties.

MIA reports provide a basis for examining parties' needs for capacity-building and technical assistance. The secretariat analyzed 39 MIA reports submitted by August 2019, and found that mercury-added products (Article 4) and mercury waste (Article 11) are recognized as priority areas by almost all the parties (Secretariat of the Minamata Convention, 2019). Other major priority areas include ASGM (Article 7), emissions (Article 8), releases (Article 9) and monitoring (Article 19).

The national mercury profile in MIA includes mercury inventory, developed using a toolkit provided by UNEP. Burton and Evers (2019) reviewed the inventories of 43 countries, and concluded that while these inventories provide valuable baseline information for these countries, the synthesis of these inventories is complicated by discrepancies between the levels and versions of the UNEP Toolkit. MIA inventories are expected to form the basis for emission and release inventories under Articles 8 and 9, and for evaluating 


\section{A tool for global regulation of mercury pollution}

the effectiveness of the Convention at the national and global levels.

Control measures under the Convention have different timelines. The obligations that have immediate effect include Article 3, which prohibits new primary mercury mining, limits the use of primary-mined mercury and excess mercury from the decommissioning of chlor-alkali facilities, and requires prior informed consent for international trade in mercury. Obligations for environmentally sound interims storage (Article 10) and environmentally sound management of mercury waste (Article 11) also have immediate effect. Timelines for other articles are summarized in Table 1. The 2020 deadline for phase-out of mercury-added products, except for those parties that registered exemption up to five years, is of particular importance, since mercuryadded products are ubiquitous in all Parties.

Another important obligation with a short timeline is the development of national action plans on ASGM. ASGM is not only the largest source of global emission and releases of mercury to the environment, but a significant challenge to the health of miners and community members. Under Article 7, all Parties that have ASGM in their territory have an obligation to reduce, and eliminate where feasible, the use of mercury in ASGM. Those Parties with more than insignificant ASGM are required to develop a national action plan (NAP). The GEF has supported 41 countries in developing NAPs. So far three plans have been submitted to the secretariat, and many others are expected to be available soon. Parties have an obligation to implement the plan, and review its progress every three years. GEF places its particular attention to ASGM, with its 45 million dollar programme called planetGOLD. This programme, implemented in Burkina Faso, Colombia, Ecuador, Guyana, Indonesia, Kenya, Mongolia and Peru, aims at unlocking capital flows to transform ASGM, integrating miners into the formal economy and regulatory system, and disseminating better practices and technology to reduce mercury and improve efficiency. The GEF Council at its meeting in June 2020 approved an additional 44 million dollar ASGM programme for Bolivia, Congo, Ghana, Honduras, Madagascar, Nigeria, Suriname and Uganda.

\section{Future challenges}

\section{Effectiveness evaluation and monitoring}

The Minamata Convention has a mechanism for evaluating its effectiveness embedded in its text. Article 22 requires the COP to evaluate the

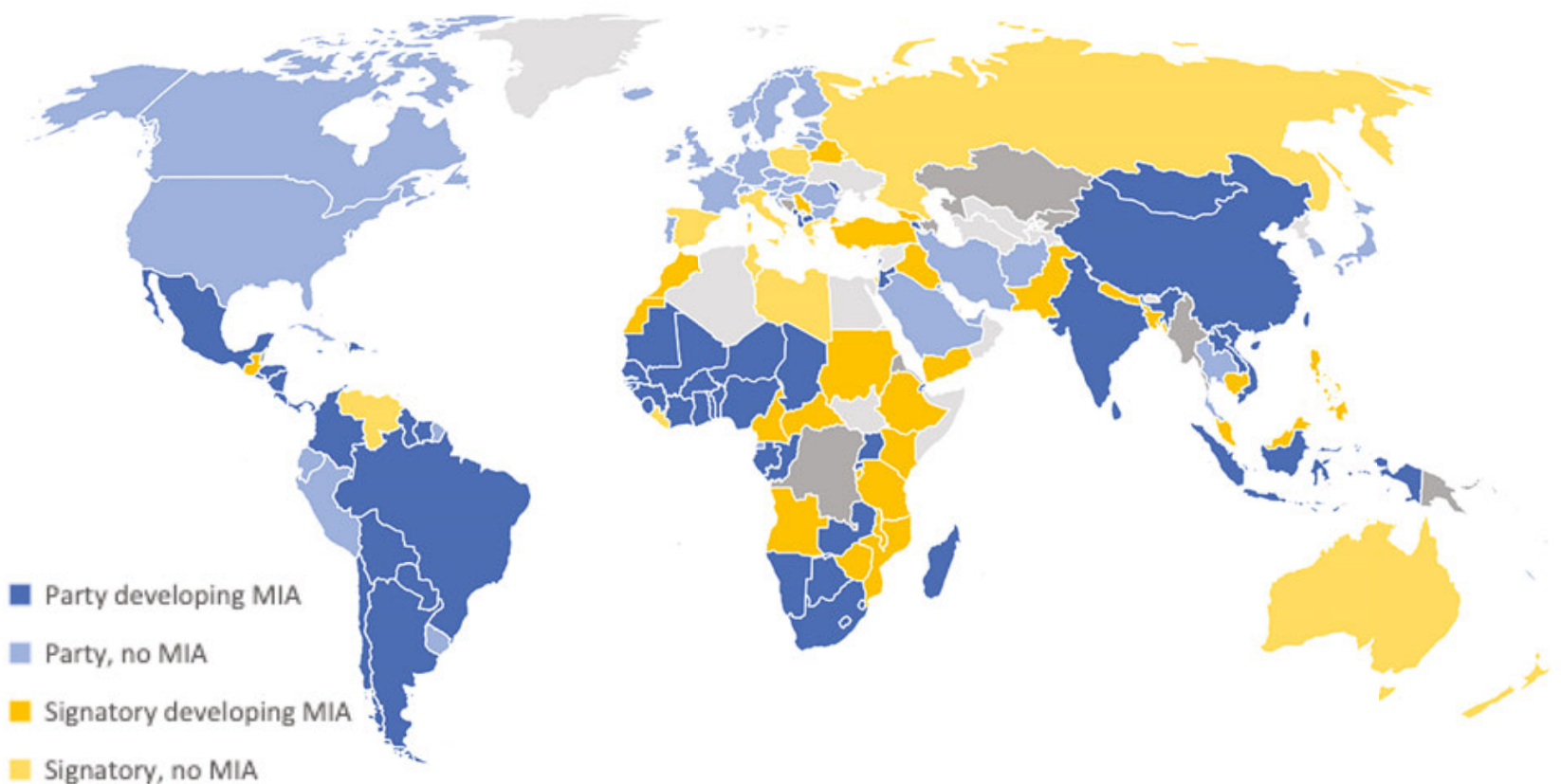

Non-party developing MIA

Non-party, no MIA

Fig. 4: Minamata Convention Parties As of 1 June 2020. Although the European Union is a party to the Convention, EU member states are colored according to whether the state is a party.

Powered by Bing. (CGeoNames, HERE, MSFT, Microsoft, NavInfo, Thinkware Extract, Wikipedia 
effectiveness of the Convention beginning no later than 6 years after the entry into force, and to initiate the establishment of arrangements for using comparable monitoring data for this purpose. COP-1 established an ad hoc group of experts consisting of members nominated by parties and observers to discuss effectiveness evaluation framework and monitoring arrangements. The group considered these issues learning from the experience of the Stockholm Convention on POPs which has a similar provision, and submitted a report to COP-2. COP gave the group a further mandate to elaborate on effectiveness evaluation framework, methodology, schedule and the use of monitoring data. The group submitted a report to COP-3.

The report proposed the following four policy questions as a basis of the effectiveness evaluation:

- Have the parties taken actions to implement the Convention?

- Have the actions taken resulted in changes in mercury supply, use, emissions and releases into the environment?

- Have those changes resulted in changes in levels of mercury in the environment, biotic media and vulnerable populations that can be attributed to the Convention?
- To what extent are existing measures under the Convention meeting the objective of protecting human health and the environment from mercury?

Sources of information were identified to address these questions, methodologies for compiling, synthesizing and integrating such information were described, and a list of indicators for evaluating individual provisions of the Convention was proposed.

COP-3 reviewed the report of the group and extensively discussed the evaluation framework. In spite of the week-long discussion at COP, it could not agree on the full details of the evaluation framework such as the terms of reference for the Effectiveness Evaluation Committee or global monitoring arrangements. The decision on the arrangements for the first effectiveness evaluation adopted at the closing minutes of COP-3 included three work elements. Firstly, COP requested the Secretariat to compile the views submitted by Parties on the evaluation indicators. The decision included a list of the proposed indicators, starting with a cross-cutting monitoring indicator for the evaluation against the Convention's objective (Article 1), followed by specific process indicators and outcome indicators responding to individual articles, organized into several clusters such as supply, demand, pressure, support,

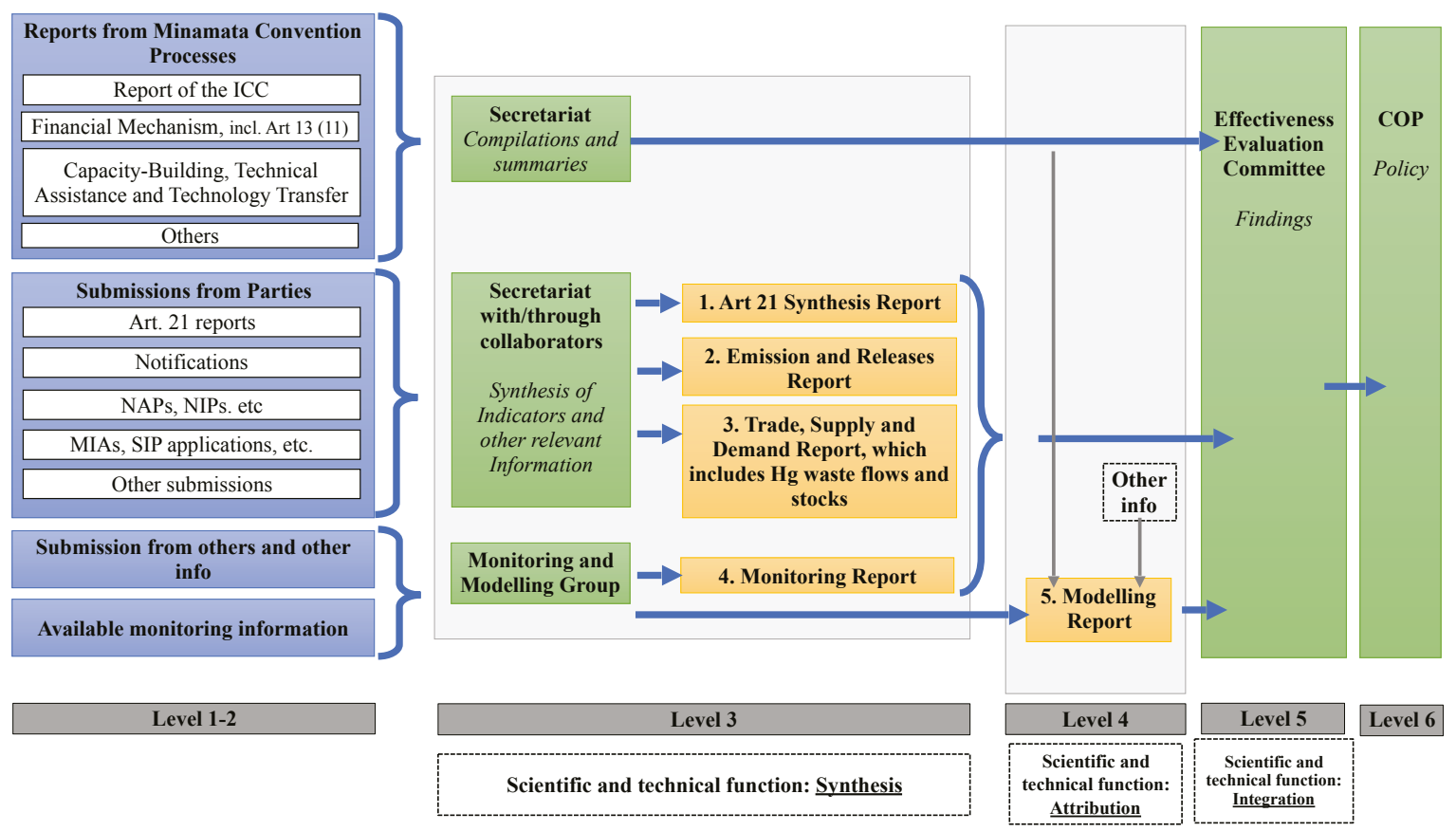

Fig. 5: Framework institutional arrangements

Abbreviations: COP, Conference of the Parties to the Minamata Convention on Mercury; ICC, Implementation and Compliance Committee; MIA, Minamata initial assessment; NAP, national action plan; NIP, national implementation plan; SIP, Specific International Programme to Support Capacitybuilding and Technical Assistance. 
information and research. Secondly, COP requested the Secretariat to work on guidance on monitoring to maintain harmonized and comparable information on mercury levels in the environment. Thirdly, it requested the Secretariat to work on a trade, supply and demand report which includes mercury waste flows and stocks, and a synthesis report on Article 21 national reporting. Other three reports, i.e. emissions and releases report, monitoring report and modelling report, although mentioned in the framework institutional arrangements (Fig. 5), were left for further discussion.

In May 2020, the Secretariat developed plans of work on indicators and monitoring guidance, in consultation with the COP-4 Bureau. Regarding indicators, the Secretariat will first develop guiding questions on the proposed indicators listed in the COP-4 decision, and convene an online information session in September 2020. Then Parties are invited to submit their initial comments by November 2020, and will have opportunities for an online exchange session. Parties are invited to submit their views by March 2021, which the Secretariat will compile into a COP-4 document.

Regarding the monitoring guidance, the work started with developing a draft annotated outline, and issuing a call for interest to contribute to the drafting. The Secretariat will convene online sessions of identified experts starting in September 2020 and draft guidance supported by consultants in air monitoring, biotic media and human biomonitoring. Draft guidance will be subject to comments from January to March 2021, and the guidance will be finalized through a final consultation meeting.

Effectiveness evaluation needs to be supported by sound science. It should be noted that Article 19 of the Convention requires Parties to cooperate to develop and improve modelling and geographically representative monitoring of levels of mercury in vulnerable populations and in environmental media. Such cooperation would support the effectiveness evaluation and effective implementation of the Convention.

Mercury levels in the atmosphere are directly linked to the anthropogenic mercury emissions addressed by the Minamata Convention. Atmospheric monitoring will indicate whether mercury levels in the air are increasing or decreasing due to the control measures, and also contribute to refining source-receptor models. Human biomonitoring has an advantage of covering exposure from all types of sources, and integrating the result of risk-reduction measures. Monitoring of the biotic media can track changes in environmental mercury levels that have ecological impact and relate to human dietary exposure. Key needs for monitoring include the following (Gustin et al., 2016):

- Development of a measurement infrastructure based on simple and affordable protocols that will enable traceable and comparable assessments of mercury and the compounds in air and their deposition;

- Development of advanced active sensors for atmospheric mercury monitoring to facilitate the extension and management of longterm monitoring programs to support policy implementation;

- Biological measurements conducted within a properly designed biomonitoring program within geographic areas of greatest concern for ecological and human health.

\section{Policy making based on sound science}

The history of the Minamata Convention started with the shared scientific knowledge on the global nature of mercury pollution. The work of INC and COP to support the implementation of the Convention, including the development of technical guidance and effectiveness evaluation, has been and will continue to be carried out on the basis of scientific and technical knowledge.

The International Conference on Mercury as a Global Pollutant (ICMGP) is an important avenue for scientific-policy interface in relation to the Convention. Established in 1990, ICMGP has worked as a primary forum to advance mercury science such as environmental and health assessment, global mercury cycle and control technology. To strengthen the linkage between the Convention and the scientific community, COP-3 included a special session on mercury science, inviting co-chairs of ICMGP 2019 (Krakow) and 2022 (Cape Town). Further collaboration is being pursued.

The Minamata Convention has an important role in the broader agenda of chemicals management, environmental protection and sustainable development. The Minamata Convention is a direct contribution to Target 3.9 of the Sustainable Development Goals to substantially reduce the number of deaths and illnesses from hazardous chemicals and air, water and soil pollution and contamination, and Target 12.4 to achieve the environmentally sound management of chemicals throughout its life cycle. Moreover, it contributes to protecting the ecosystem services, by reducing the mercury levels in fish and other food and thus enhancing the life-supporting capacity of the global ecosystem. It also protects the wildlife, especially in the polar region where scientific evidence 
indicates significant concern of mercury exposure for many species (AMAP 2018). Policy measures on ASGM will bring about multi-faceted benefits on protecting ecosystems and preventing land degradation, as well as protecting human health and improving the livelihood of local communities.

Link between the Minamata Convention and climate change should also be highlighted. Climate change affects the global cycle of mercury with increased volatility, forest and peat fires, melting permafrost, etc. Reducing dependence on coal will have a co-benefit of reducing mercury emission. Common technologies are used for controlling the emission of mercury, black carbon and other air pollutant. While the global community faces the challenge of "building back better" from the COVID-19 pandemic with reduced environmental footprint, Minamata Convention forms part of the transformational change towards a healthy planet.

Sound science is at the center of strengthening synergies between multilateral environmental agreements and other global actions for environmental protection and sustainable development.

\section{References}

1. AMAP. 2018. AMAP Assessment 2018: Biological effects of contaminants on Arctic wildlife and fish. Arctic Monitoring and Assessment Programme (AMAP), Tromsø, Norway. vii+84pp; https://www.amap.no

2. Burton, M.E.H. and Evers, D.C. 2019. Global Mercury Inventory Synthesis: An Initial Examination of the MIA Mercury Inventories. Biodiversity Research Institute. Portland, Maine. Biodiversity Research Institute (BRI) Report 2019-18.

3. Gustin M.S., Evers D.C., Bank M.S., Hammerschmidt C.R., Pierce A., Basu N., Blum J., Bustamante P., Chen C.,
Driscoll C.T., Horvat M., Jaffe D., Pacyna J.M., and Pirrone N. 2016. Importance of Integration and Implementation of Emerging and Future Mercury Research into the Minamata Convention. Environ. Sci. Technol., 50, 6, 2767-2770, https://doi.org/10.1021/acs.est.6b00573

4. Pacyna J.M., Travnikov O., De Simone F., Hedgecock I.M., Sundseth K., Pacyna E.G., Steenhuisen F., Pirrone N., Munthe J. and K. Kindbom. 2016. Current and future levels of mercury atmospheric pollution on global scale. Atmos. Chem. Phys., 16, 12495-12511, https://doi. org/10.5194/acp-2016-370.

5. Secretariat of the Minamata Convention. 2019. Analysis of national priorities from Minamata Initial Assessments. Available from http://www. mercuryconvention.org/News/fromtheConvention/ ICMGP2019/tabid/8131/language/en-US/Default.aspx

6. UNEP. 2002. Global mercury assessment.

7. UNEP. 2006. Summary of supply, trade and demand information on mercury.

8. UNEP. 2008. The global atmospheric mercury assessment: sources, emissions and transport.

9. UNEP. 2013. Global mercury assessment 2013; http:// hdl.handle.net/20.500.11822/7984

10. UNEP. 2017. Global mercury supply, trade and demand; https://www.unenvironment.org/resources/report/ global-mercury-supply-trade-and-demand

11. UNEP. 2019. Global Mercury Assessment 2018; https:// www.unenvironment.org/resources/publication/globalmercury-assessment-2018

Eisaku Toda is Senior Programme Officer and Claudia ten Have is Senior Policy Coordination Officer, both from the Secretariat of the Minamata Convention on Mercury, United Nations Environment Programme. The views expressed in this article are those of the author and do not necessarily reflect the views of the United Nations.

Jozef M. Pacyna is Professor at AGH University of Science and Technology, Krakow, Poland.

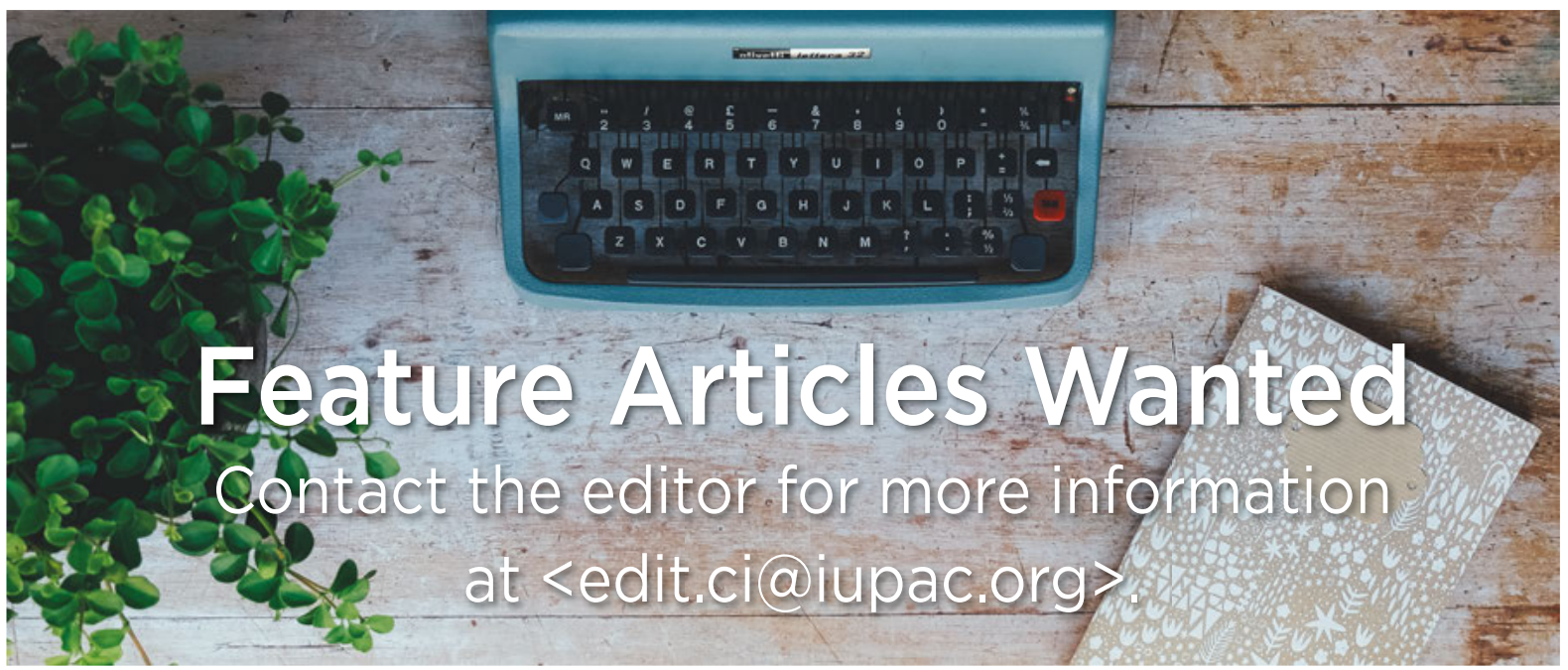

